\title{
Knowing what we don't know: cognitive correlates of early spelling of different target types
}

\author{
Elise de Bree ${ }^{1} \cdot$ Madelon van den Boer $^{1}$
}

Published online: 7 March 2019

(c) The Author(s) 2019

\begin{abstract}
Although research on cognitive correlates of spelling has been conducted, these studies generally do not distinguish between different types of targets that need to be spelled. Arguably, the contributions of these skills differ for words opposed to pseudowords and for targets that can be spelled on the basis of phoneme-to-grapheme conversion (phonologically consistent) and those that cannot (phonologically inconsistent, relying on orthographic knowledge). We assessed these issues in early spelling. A total of 83 first graders and 58 second graders completed word and pseudoword dictation tasks, containing phonologically consistent and inconsistent items. They also completed tasks reflecting potential cognitive correlates of spelling: phoneme awareness, rapid automatized naming, visual attention span and word reading. Dictation outcomes demonstrated that more spelling errors were made in inconsistent than in consistent items. The effect of lexicality differed across grades: More errors were made in spelling words than pseudowords in Grade 1, whereas the opposite pattern was found in Grade 2. Phoneme awareness and rapid naming, but not visual attention span, were found to be significant correlates of spelling outcomes. However, the cognitive correlates captured only a limited amount of variance in spelling errors. Moreover, these effects mostly disappeared once word reading was entered as a predictor. These findings indicate that research into predictors of spelling should distinguish between words and pseudowords, consistent and inconsistent items, and should consider more spelling-based rather than reading-based correlates of spelling performance.
\end{abstract}

Keywords Consistency · Phoneme awareness · Rapid automatised naming · Spelling · Visual attention span · Word type

Elise de Bree and Madelon van den Boer have contributed equally to this work.

Elise de Bree

e.h.debree@uva.nl

Madelon van den Boer

m.vandenboer@uva.nl

1 Research Institute of Child Development and Education, University of Amsterdam, PO Box 15780, 1001 NG Amsterdam, The Netherlands 


\section{Introduction}

Spelling ability is an important component of being literate. For one, it is an important element in grading the content of a written piece of text (Graham, Harris, \& Hebert, 2011) and affects writing ability (Abbott, Berninger, \& Fayol, 2010; Tops, Callens, Van Cauwenberghe, Adriaens, \& Brysbaert, 2013). Furthermore, spelling ability is one of the determinants of school achievement and secondary education (Savolainen, Ahonen, Aro, Tolvanen, \& Holopainen, 2008). Given this importance of spelling, insight into spelling acquisition is needed. In this study, we assess early spelling in Dutch, an orthography that is transparent for reading, as grapheme to phoneme conversion is relatively straightforward, but less so for spelling, as phoneme to grapheme conversion is more complicated (Bosman, Vonk, \& van Zwam, 2006). We look into the relation of concurrent cognitive correlates with early spelling by including phonological awareness (PA), rapid automatized naming (RAN) as well as visual attention span (VAS). Furthermore, we look at these predictors in relation to spelling words and pseudowords differing in phonological consistency.

Cognitive correlates of spelling have been assessed both concurrently and longitudinally (e.g., Caravolas, Volín, \& Hulme, 2005; Georgiou, Torppa, Manolitsis, Lyytinen, \& Parrila, 2012; Kim, 2010; Lervåg \& Hulme, 2010; Moll et al., 2014; Veber Nielsen \& Juul, 2016). However, to our knowledge, the relationship between early spelling (Grade 1 and 2) and the joint assessment of the role of PA, RAN and VAS has not been investigated, whereas all three might relate to spelling. Furthermore, studies have typically not differentiated between different target types in establishing this relationship between correlates and spelling outcomes. It might, however, be the case that spelling different target types relies on different cognitive skills. In particular, spelling of phonologically consistent items, relying on phoneme-to-grapheme conversion, might require different skills than phonologically inconsistent items, relying on the application of spelling rules or memorization.

Although studies into spelling predictors have typically collapsed different target types as one spelling outcome, some studies have looked into the role of cognitive correlates and different spelling targets. In their study into longitudinal predictors of beginning spelling in Norwegian, Lervåg and Hulme (2010) distinguished between word and pseudoword spelling. They found an overlap in the predictors for both types of targets. PA, RAN, letter knowledge and verbal short-term memory related to both word and pseudowords spelling. However, they also found a difference in predictors, as paired associated learning (PAL) contributed to pseudoword spelling, but not to word spelling. PAL refers to the ability to learn associations between visual stimuli and their verbal labels and is generally assessed by having participants learning to pair pseudoword names to pictures. These findings point to some differences in cognitive predictors of different target types. It should be noted, however, that the words assessed by Lervåg and Hulme contained both consistently and inconsistently spelled targets, whereas the pseudowords contained mainly consistent targets. A further distinction based on spelling consistency is thus warranted.

Kim, Petscher, and Park (2016) assessed spelling development in Korean children from prekindergarten to kindergarten. Targets included transparent words, 
in which phonemes and graphemes are mapped directly, as well as words whose spellings were determined by phonological shifts. In these words with phonological shifts, morphological operations take place that alter the pronunciation of the word, but not the orthography. Such shifts thus lead to differences in orthographic transparency. Kim et al. found that spelling correct scores of high frequent words differing in transparency were determined both by target type and emergent literacy skills, the latter encompassing phonological, orthographic and morphological awareness, as well as vocabulary and letter naming fluency. In terms of target characteristics, targets with higher transparency were spelled better than those with lower transparency. In terms of child characteristics, higher emergent literacy skills, which were treated as one factor, of the child were related to higher spelling accuracy scores. The study by Kim et al. thus provides important information on the contribution of child skills to spelling different target types. In this study, we sought to expand that knowledge by assessing whether spelling of consistent and inconsistent words and pseudowords relate differently to PA and RAN. We also added VAS as an early cognitive predictor.

Although initially related to word reading, PA and RAN have also been shown to predict spelling outcomes. PA refers to the ability to perceive, store, and manipulate phonological information. This ability is pivotal in relating graphemes to phonemes and vice versa, such as for understanding the alphabetic principle. Indeed, PA has been reported to play a role in concurrent (e.g., Al-Otaiba et al., 2010; Kim, 2010; Moll et al., 2014) and longitudinal spelling ability (e.g., Caravolas et al., 2012; Harrison et al., 2016; Landerl \& Wimmer, 2008; Lervåg \& Hulme, 2010; Veber Nielsen \& Juul, 2016; Verhagen, Aarnoutse, \& van Leeuwen, 2010), although not all studies report a contribution of PA to spelling (Georgiou et al., 2012). An influence of PA on spelling outcomes is anticipated for spelling ability across the board, as this skill is required to convert phonemes to graphemes. It might be most visible in phonologically consistent targets, and also in pseudowords, which do not have a semantic or lexical orthographic representation to rely on. However, an effect might also be present for phonologically inconsistent targets, as errors in spelling these targets might be based on phoneme-to-grapheme mapping instead of the application of spelling rules and orthographic knowledge.

The second correlate related to spelling is RAN, referring to the ability to pronounce the names of sequentially and repeatedly presented familiar visual stimuli, such as letters, digits, colours or objects. In studies of literacy skills alphanumeric RAN (letters and digits) generally shows a stronger relationship to literacy than nonalphanumeric RAN (colours and objects; e.g. van den Bos, Zijlstra, \& Lutje Spelberg, 2002), also for spelling specifically (Savage, Pillay, \& Melidona, 2008). While RAN performance has been associated with spelling ability concurrently (e.g., Moll et al., 2014; Savage et al., 2008) and longitudinally (e.g., Caravolas et al., 2012; Furnes \& Samuelsson, 2011; Harrison et al., 2016; Savage et al., 2008; Veber Nielsen \& Juul, 2016), the contribution of RAN to spelling ability is not always reported (e.g., Landerl \& Wimmer, 2008; Moll et al., 2014; Nikolopoulos, Goulandris, Hulme, \& Snowling, 2006; Vaessen \& Blomert, 2013). These mixed findings speak to the issue of the skills RAN performance reflects and relate to the influence RAN has at different ages and for different word types. 
In one view, alphanumeric RAN ability relates to the automaticity of orthography to phonology associations (Moll, Fussenegger, Willburger, \& Landerl, 2009). In this view, RAN is expected to contribute to early spelling, as it taps the efficiency of the alphabetic principle, similar to PA. A pronounced influence of RAN on early spelling acquisition has indeed been reported (Lervåg \& Hulme, 2010; Veber Nielsen \& Juul, 2016; Verhagen et al., 2010). An alternative view is that RAN taps the ability to construct and store orthographic representations of words or parts of words (e.g., Conrad \& Levy, 2007; Wolf \& Bowers, 1999). According to this view, the effect of RAN might become more pronounced later in development, as orthographic representations are constructed over time. RAN might then have a limited influence on early spelling, as basic orthographic knowledge is still being acquired. Furthermore, an influence would most likely surface for word spelling, more than for pseudoword spelling, as word-specific orthographic representations can be constructed for the known targets only. In contrast to this latter account, however, the study by Lervåg and Hulme (2010) showed that RAN contributed to the development of spelling for both words and pseudowords. Another expectation on the basis of the view that RAN taps orthographic representations is that RAN might influence spelling of phonologically inconsistent targets more than of consistent targets, as orthographic knowledge is especially required to spell these targets. Clearly, more research is needed to unravel the relation between RAN and spelling.

A skill that has been proposed more recently to relate to literacy development is VAS, referring to the number of sublexical orthographic units, such as letters or clusters, that can be processed simultaneously in one glance (e.g., Valdois, Bosse, \& Tainturier, 2004; Valdois et al., 2003). VAS has been shown to relate to word reading performance over and above phonological skills in children both with and without dyslexia in various languages (Bosse, Tainturier, \& Valdois, 2007; Bosse \& Valdois, 2009; Germano, Reilhac, Capellini, \& Valdois, 2014; van den Boer, van Bergen, \& de Jong, 2015; Zoubrinetzky, Bielle, \& Valdois, 2014). So far, however, there are hardly any longitudinal studies on the relation between VAS and literacy skills (but see van den Boer \& de Jong, 2018), and limited attention has been devoted to the role of VAS in spelling. The current study is the first to examine the relation of VAS with early spelling and spelling of different target types. In a previous study on VAS and spelling in fourth graders, van den Boer et al. (2015) found that VAS contributed to word spelling, after controlling for PA and RAN, reading fluency and orthographic knowledge. Visual search ability is a general ability in which nonlinguistic symbols have to be identified amongst distractor symbols. It is similar to VAS in tapping visual attention and analysis of symbols. This visual search ability has been found to be an important predictor of spelling in Grade 1 (Plaza \& Cohen, 2007). It is not yet clear how visual attention in general, and VAS in particular, relate to spelling from the end of Grade 1 onwards and whether visual skills relate differently to spelling of different target types.

Related, the findings on reading and spelling have led to a debate about the nature of VAS. On the one hand, it has been suggested that VAS is first and foremost a visual task and that relations with literacy skills stem from the role VAS has in the extraction and storage of orthographic information during reading (e.g., Bosse, Chaves, Largy, \& Valdois, 2015; Valdois et al., 2004). In line with this interpretation, 
it has been found that children with a specific disorder in VAS scored poorly on word spelling, but did not differ from age-matched controls in spelling of pseudowords (Zoubrinetzky et al., 2014). If this interpretation is correct, we would expect at least a smaller effect of VAS on pseudoword than on word spelling, although the effect of VAS on spelling could be limited in all spelling conditions, since the beginning readers and spellers of the current study are still developing basic orthographic knowledge.

On the other hand, the findings concerning VAS, which is typically measured as the ability to report back briefly presented letter strings, have led to the conclusion that VAS taps grapheme-phoneme connections, or verbal coding abilities, in addition to or instead of visual processing skills (Hawelka \& Wimmer, 2008; Ziegler, Pech-Georgel, Dufau, \& Grainger, 2010). However, VAS has been shown to relate to both reading and spelling, over and above phonological processing skills (van den Boer et al., 2015), which also clearly capture grapheme-phoneme connections. Therefore, van den Boer et al. (2015) suggested that VAS might reflect the parallel processing of orthographic units, and simultaneously, parallel activation of the corresponding phonological units. If this interpretation is correct, VAS relates more to sublexical orthographic knowledge and we would expect VAS to relate to spelling of words, but also of pseudowords, and we would expect an effect of VAS also in the very early stages of spelling development. Concerning phonological consistency, the expectations would be similar to PA. We expect VAS to relate to consistent items, and potentially to the errors made in inconsistent targets.

Although PA, RAN and VAS are commonly studied as predictors of spelling and can conceptually all be related to spelling, they are generally studied as predictors of reading. Given the association of these cognitive correlates with reading, early spelling might be predicted best by word reading itself, as word reading might subsume the effects of PA, RAN and VAS. Furthermore, both reading and spelling demand lexical representations (Perfetti, 1997) with intertwined word meaning, phonological and orthographic representations. Word reading is thus expected to exert an influence on spelling in early grades, as has been reported (Desimoni, Scalisi, \& Orsolini, 2012; Keuning \& Verhoeven, 2008; Leppänen, Nieme, Aunola, \& Nurmi, 2006). We therefore also included word reading as a correlate of spelling outcomes. Concerning the different target types, the effect of word reading might be stronger for words than pseudowords, and especially strong for phonologically inconsistent words, that rely most on orthographic knowledge.

In sum, in the present study we look into the role of PA, RAN and VAS in Grade 1 and 2 spellers. We assess whether the contribution of these correlates is the same for different target types. The targets are divided by phonological consistency (consistent and inconsistent targets) and lexicality (words and pseudowords). This consistency is related to vowel spelling, which can be determined by a transparent phoneme-grapheme connection or by orthographic conventions (e.g., Landerl \& Reitsma, 2005). A previous study assessed the influence of item characteristics (phonology, morphology, word and vowel frequency, orthographic familiarity) on vowel spelling (de Bree, Geelhoed, \& van den Boer, 2018) and found that all item characteristics contributed to the spelling pattern. However, this study did not look into the association between emergent literacy skills and spelling of the different 
target categories. Such an approach is, however, also important for our understanding of the development of spelling.

Spelling of consistent targets is expected to contain fewer errors than inconsistent targets. Spelling of words is expected to render better performance than spelling of pseudowords, for which no lexical representations are available (Perfetti, 1997). PA is expected to influence early spelling of all target types. If RAN and VAS tap into lexical orthographic skills, then their effects might be limited, as lexical orthographic representations might not have been formed in these young spellers yet. In contrast, if RAN and VAS also reflect phonology-orthography connections and sublexical orthographic knowledge, then their contributions might be visible in both words and pseudowords and consistent and inconsistent targets.

\section{Method}

\section{Participants}

A total of 141 children participated in this study (58 girls, mean age $=7$ years 3 months, $S D=7.18$ months). All children were attending mainstream primary education in one of four participating schools. There were 83 children in Grade 1 ( 31 girls, mean age $=6$ years 10 months, $S D=4.45$ months) and 58 children in Grade 2 (27 girls, mean age $=7$ years 9 months, $S D=5.43$ months). From the total sample, $22.0 \%$ spoke at least one other language at home in addition to Dutch. Spelling ability of the children measured through standardized curriculum based measures showed an average to slightly below average score both in Grade $1(\mathrm{M}=3.10$, $S D=1.52$ out of 5 , with 5 being the lowest $)$ and Grade $2(\mathrm{M}=3.75, S D=1.32)$.

\section{Measures}

\section{Spelling ability}

Spelling ability was assessed with a dictation task consisting of four parts. Parts 1 through 3 included words, whereas part 4 contained pseudowords.

\section{Word spelling}

Word spelling dictation consisted of phonologically consistent and inconsistent words. Consistency was determined on the basis of vowel spelling: there were 25 words whose vowel spelling was consistent: these refer to vowel spellings similar to their pronunciation (e.g., maan moon). There were 33 words with phonologically inconsistent vowel spellings. These are targets in which long vowels are spelled with only one grapheme (e.g., water water). This spelling is determined by an orthographic rule (e.g., Landerl \& Reitsma, 2005).

The consistent targets included 15 monosyllabic words and 10 compounded words (e.g., rugzak backpack, spaarpot piggy bank). The number of graphemes varied 
between 3 and 8 (mean 5.2). The inconsistent targets consisted of 32 bisyllabic words and one trisyllabic word as inconsistent vowel spelling does not arise in monosyllabic words. The items were similar to the consistent targets in the number of graphemes, with a range of graphemes of 4 to 7 graphemes, and a mean of 5.3. The words were specifically selected for another study on vowel spelling in children (de Bree et al., 2018), in which targets were selected on the basis of different vowels and word classifications. This accounts for the fact that the number of consistent and inconsistent targets is not equal in the present study. The items consisted of words known to children (e.g., consistent been 'leg' and inconsistent lepel 'spoon'), as well as words likely to be unfamiliar in either meaning, orthography or both (e.g., consistent koopman 'merchant' and inconsistent krater 'crater'). In the current study, these word categories were all grouped together to reflect overall word spelling of consistent versus inconsistent items and together constitute a broad range of spelling requirements. Mean word frequency on the basis of CELEX (Baayen, Piepenbrock, \& van Rijn, 1993) did not differ between the consistent (69.0) and inconsistent words (76.9), $t(52)=-.440, p=.662$. The items are presented in "Appendix 1".

The words were embedded in short sentences. Children were presented first with the target word, then with the sentence, and then again with the target word (e.g., 'Maan. Vannacht is het volle maan. Schrijf op 'maan'"Moon. Tonight it is full moon. Write down 'moon'). The scores consisted of the average number of errors per word, calculated separately for consistent and inconsistent words. Counted as errors were incorrectly spelled letters (vogel as * fogel bird), letters that were missing (krater as *kater crater), and letters that were added (water as *waater water). Coding was done by both authors. The first 50 items were scored together. In cases of doubt, items were discussed. In all instances, there was agreement on the coding. Internal consistency of the final error scores between the words was .95 , with an internal consistency of .76 and .95 for only consistent and only inconsistent words respectively.

\section{Pseudoword spelling}

Following the same procedure as for the dictation of words, one dictation containing 24 pseudowords was administered. Eight items were consistent monosyllabic pseudowords containing a long vowel (e.g., muut, naag). The other 16 items were inconsistent bisyllabic pseudowords containing a long vowel written as a short vowel (dovel, veken). Mean number of graphemes of the consistent pseudowords was 4.3 and of inconsistent pseudowords 5.2. Error coding was the same as for the real words. Internal consistency of the final error scores between the pseudowords was .90 , with an internal consistency of .67 and .90 for only consistent and only inconsistent pseudowords respectively.

\section{Cognitive correlates}

\section{Word reading}

To assess word reading, we used the One Minute Test (Eén Minuut Test; Brus \& Voeten, 1995), a standardized test of word reading fluency. Children were presented 
with a list of 116 words of increasing difficulty, and were asked to read the words aloud as quickly and accurately as possible for $1 \mathrm{~min}$. The timed word reading task contains both consistent words (such as zoom 'hem' and staaf 'bar') as well as inconsistent words, like the ones examined in our spelling task (for example words tafel 'table' and lever, 'liver'). These words, however, are inconsistent mainly in the direction of phoneme to grapheme conversion (spelling) rather than the grapheme to phoneme conversion. The score consisted of the number of words read correctly. Parallel-forms reliability is between .89 and .97 (Brus \& Voeten, 1995).

\section{Pseudoword reading}

To assess pseudoword reading, we used the Klepel (van den Bos, Lutje Spelberg, Scheepstra \& de Vries, 1994), a standardized test of pseudoword reading fluency. Children were presented with a list of 116 pseudowords of increasing difficulty, and were asked to read the pseudowords aloud as quickly and accurately as possible for 2 min. The timed pseudoword reading task contains both consistent pseudowords (such as 'zoof' and 'jeef') and inconsistent pseudowords, like the ones examined in our spelling task (for example pseudowords 'fasel' and 'kovel'). These words, however, are inconsistent mainly in the direction of phoneme to grapheme conversion (spelling) rather than the grapheme to phoneme conversion. The score consisted of the number of items read correctly. Parallel-forms reliability is between .89 and .95 (van den Bos et al., 1994).

\section{PA}

PA was assessed with a phoneme deletion task (de Jong \& van der Leij, 2003). Children were presented with a pseudoword, which they were asked to repeat. Next, the pseudoword was repeated by the experimenter and children were asked to delete one phoneme (e.g., 'tesp' without 'p'). The task contained 12 items, divided over three sets. The first four items were monosyllabic pseudowords, the next four items were bisyllabic pseudowords, and the last four items were bisyllabic pseudowords with the phoneme to be deleted included twice (e.g., 'griesglaak' without 'g'). Three practice items preceded the first set, and another two were presented before the third set. The score consisted of the number of items correct. The task was discontinued when all items within a set were incorrect. Internal consistency was .85 in the current sample, and split-half reliability was .71.

\section{RAN}

RAN digits $(2,4,5,8,9)$ and letters (a, d, o, p, s) were assessed with subtests of the test for Continuous Naming and Word Reading (Continu Benoemen \&Woorden Lezen; van den Bos \& Lutje Spelberg, 2007). Children were presented with five columns of ten items each, and were asked to name all 50 items as quickly and accurately as possible. The score consisted of the average number of digits and letters named correctly per second. Split-half reliability is .87 for digits and .82 for letters (van den Bos \& Lutje Spelberg, 2007). 


\section{VAS}

VAS was assessed with a whole report task (Valdois et al., 2003). Children were first presented with 10 five-letter strings (e.g., B R T P S), and then with 10 fivedigit strings (e.g., 84219 ). They were asked to repeat each string as accurately as possible, in the correct order. The strings were created from ten consonants $(\mathrm{B}, \mathrm{D}$, F, H, L, M, P, R, S, T) and ten digits (0-9), all presented once in each position. The task was presented using Microsoft PowerPoint 2010. A plus sign was presented for $1000 \mathrm{~ms}$ to focus attention, followed by the string, presented for $200 \mathrm{~ms}$ in 28-point Arial font. The scores consisted of the total number of letters and digits repeated correctly in the correct order (with a maximum of 100). Internal consistency was .94 for digits and .95 for letters in the current sample, and split-half reliability .90 for digits and .94 for letters.

\section{Procedure}

Participants were recruited through primary schools and tested in the spring. In three schools Grade 1 participated, in one school Grade 2 and in one school Grades 1 and 2. When a school agreed to participate all children in Grade 1 and/or 2 were included in the study. No exclusion criteria were applied. Parents provided passive informed consent. The study was approved by the ethics committee of the $<$ blinded $>$.

The dictation task was administered in four separate classroom sessions of about $30 \mathrm{~min}$ each. Sessions 1 to 3 consisted of dictations of real words, whereas pseudowords were presented in session 4 . Testing took place within the time span of 1 to 1,5 week. Generally testing was conducted every day consecutively for the four sessions, always at the same time of the day. In addition, children were administered the reading tasks, as well as tasks measuring cognitive correlates of spelling, in an individual session of about $30 \mathrm{~min}$. The data were collected by trained assistants. Teachers were present during the classroom sessions.

\section{Results}

\section{Data cleaning}

Before running analyses the data were checked for missing values and outliers, as well as score distributions. For spelling of words, scores of five children were removed from the dataset because they had missed two out of three dictation sessions. In addition, error scores of two children on word spelling and of three children on spelling of consistent words specifically were found to be more than three standard deviations above the mean, and were therefore left out of the analyses. For spelling of pseudowords, scores of six children were missing because they were absent during the dictation session. In addition, the error score of one child on pseudoword spelling and of four children on spelling of consistent 
pseudowords specifically were found to be outliers and were left out of the analyses. For reading and the cognitive correlates there were no missing values or outliers. After data cleaning scores on all variables were normally distributed.

\section{Spelling of phonologically consistent and inconsistent words and pseudowords}

The exact $N$ for each variable, as well as means and standard deviations are presented in Table 1, for each grade separately. A 2 (word, pseudoword) by 2 (consistent, inconsistent) by 2 (Grade 1, Grade 2) repeated measures ANOVA was conducted. As expected, consistent items were spelled much better than inconsistent items, $F(1123)=847.25, p<.001, \eta_{\mathrm{p}}^{2}=.873$, and second graders made fewer spelling errors than first graders, $F(1123)=25.72, p<.001, \eta_{\mathrm{p}}^{2}=.173$. There was no overall difference between word and pseudoword spelling, $F(1123)=2.63$, $p=.107, \eta_{\mathrm{p}}^{2}=.021$, and the effect of consistency was the same for words and pseudowords, $F(1123)=0.34, p=.854, \eta_{\mathrm{p}}^{2}=.000$. First graders made more errors in spelling words than pseudowords, whereas second graders made more errors in spelling pseudowords than words, $F(1123)=33.44, p<.001, \eta_{\mathrm{p}}^{2}=.214$. In addition, the difference between consistent and inconsistent words was larger in Grade 1 than in Grade 2, $F(1123)=21.76, p<.001, \eta_{\mathrm{p}}^{2}=.150$. Furthermore, a significant three-way interaction between Grade, word type and consistency, $F(1123)=17.26, p<.001, \eta_{\mathrm{p}}^{2}=.123$, was found, indicating that first graders spelled inconsistent words especially poorly, whereas second graders spelled inconsistent pseudowords most poorly.

Table 1 Descriptive statistics of mean number of errors and cognitive correlates per grade and target type

\begin{tabular}{|c|c|c|c|c|c|c|}
\hline & \multicolumn{3}{|c|}{ Grade 1} & \multicolumn{3}{|c|}{ Grade 2} \\
\hline & $N$ & $M(S D)$ & range & $N$ & $M(S D)$ & range \\
\hline \multicolumn{7}{|l|}{ Spelling $^{\mathrm{a}}$} \\
\hline Words & 76 & $.98(.33)$ & $.07-1.98$ & 58 & $.55(.26)$ & .05-1.17 \\
\hline Consistent & 75 & $.30(.19)$ & $.00-.76$ & 58 & $.16(.14)$ & $.00-.58$ \\
\hline Inconsistent & 78 & $1.55(.52)$ & $.13-3.00$ & 58 & $.86(.41)$ & .06-1.77 \\
\hline Pseudowords & 80 & $.90(.44)$ & $.17-1.96$ & 54 & $.77(.32)$ & $.00-1.38$ \\
\hline Consistent & 78 & $.19(.20)$ & $.00-.88$ & 53 & $.16(.20)$ & $.00-.75$ \\
\hline Inconsistent & 81 & $1.27(.62)$ & $.25-2.75$ & 54 & $1.06(.42)$ & .00-1.88 \\
\hline \multicolumn{7}{|l|}{ Correlates } \\
\hline Word reading & 83 & $22.93(14.32)$ & $6-72$ & 58 & $39.09(13.61)$ & $11-68$ \\
\hline Pseudoword reading & 83 & $21.46(13.28)$ & $4-69$ & 58 & $30.45(15.83)$ & $9-64$ \\
\hline PA & 83 & $4.00(3.08)$ & $0-11$ & 58 & $4.66(3.22)$ & $0-12$ \\
\hline RAN & 83 & $1.27(.27)$ & $.62-1.93$ & 58 & $1.63(.30)$ & $.92-2.28$ \\
\hline VAS & 83 & $49.75(19.84)$ & $9-89$ & 58 & $53.48(22.69)$ & $15-94$ \\
\hline
\end{tabular}

${ }^{\mathrm{a}}$ In average number of errors per item 


\section{Cognitive correlates of spelling}

The correlations between all the variables are presented in Table 2. The correlations between the different measures of spelling (errors) are higher for words than for pseudowords and higher for the inconsistent than for the consistent items. Please note that the correlations of spelling with reading and cognitive correlates are expected to be negative, since the spelling scores reflect the average number of errors per item, with higher scores reflecting poorer performance. All spelling measures correlated significantly with word reading, but correlations were higher with word than with pseudoword spelling and higher with spelling of inconsistent than consistent items. PA correlated significantly with all spelling scores, but mostly with word spelling, especially spelling of inconsistent words. RAN also correlated with all spelling scores, but more strongly with word than pseudoword spelling. VAS correlated only with word spelling, and correlations were weaker than with the other two cognitive correlates.

We used regression analyses to examine whether reading and the cognitive correlates had a unique relation with spelling. The results are reported in Table 3. When only the cognitive correlates were included in the analyses, a small portion of variance in the spelling measures was explained. Spelling of consistent and inconsistent words significantly related to PA and RAN. Spelling of consistent and inconsistent pseudowords significantly related to PA, RAN, and VAS. However, the effect of VAS was not in the expected direction. This appears to reflect a suppression effect, which can occur when a variable does not correlate with the dependent variable, but does correlate with one of the independent variables (Maassen \& Bakker, 2001). VAS correlates quite strongly with word reading and PA, and to lesser extent also with RAN (see Table 2). These relations among predictors are reflected in the regression coefficient of VAS, indicating that the relation of PA and RAN with spelling is due to characteristics of the tasks that are not shared with VAS. However, a suppression

Table 2 Correlations between spelling errors, cognitive correlates and word reading

\begin{tabular}{|c|c|c|c|c|c|c|c|c|c|}
\hline & 1 & 2 & 3 & 4 & 5 & 6 & 7 & 8 & 9 \\
\hline 1. Words consistent & - & & & & & & & & \\
\hline $\begin{array}{l}\text { 2. Words inconsist- } \\
\text { ent }\end{array}$ & $.637 * *$ & - & & & & & & & \\
\hline $\begin{array}{l}\text { 3. Pseudowords } \\
\text { consistent }\end{array}$ & $.331 * *$ & $.250 * *$ & - & & & & & & \\
\hline $\begin{array}{l}\text { 4. Pseudowords in } \\
\text { consistent }\end{array}$ & $.444 * *$ & $.622 * *$ & $.478 * *$ & - & & & & & \\
\hline 5. Word reading & $-.551 * *$ & $-.762 * *$ & $-.174 *$ & $-.313 * *$ & - & & & & \\
\hline $\begin{array}{l}\text { 6. Pseudoword } \\
\text { reading }\end{array}$ & $-.428 * *$ & $-.658 * *$ & $-.188 *$ & $-.309 * *$ & $.899 * *$ & - & & & \\
\hline 7. PA & $-.337 * *$ & $-.480 * *$ & $-.176^{*}$ & $-.196^{*}$ & $.598 * *$ & $.582 * *$ & - & & \\
\hline 8. RAN & $-.418 * *$ & $-.458 * *$ & $-.239 * *$ & $-.239 * *$ & $.569 * *$ & $.465^{* *}$ & $.295 * *$ & - & \\
\hline 9. VAS & $-.253 * *$ & $-.275^{* *}$ & .058 & .109 & $.491 * *$ & $.429 * *$ & $.459 * *$ & $.325 * *$ & - \\
\hline
\end{tabular}

$* p<.05, * * p<.01$ 
effect can also be reflected in the regression coefficients of the other predictors. As VAS does not correlate with spelling of pseudowords, we left it out of the regression models to obtain clearer results. When VAS was left out of the analyses, spelling of consistent pseudowords was significantly predicted by RAN $(\beta=-.206, p=.022)$, but not by PA $(\beta=-.119, p=.180)$, as was spelling of inconsistent pseudowords (RAN: $\beta=-.198, p=.026$; PA: $\beta=-.136, p=.125$ ).

Next, reading ability was added to the regression analyses. Because word and pseudoword reading correlated strongly, but word reading correlated slightly stronger with spelling, we chose to include word but not pseudoword reading. With word reading included, the explained variance increased slightly for spelling of consistent words and inconsistent pseudowords, quite strongly for spelling of inconsistent words, but not for consistent pseudowords. For spelling of consistent words, inconsistent words and inconsistent pseudowords, word reading was a significant correlate. For spelling of inconsistent items, a suppression effect of VAS was again found. When VAS was left out of the analyses, spelling of inconsistent words was related only to reading $(\beta=-.714, p<.001)$, as was spelling of inconsistent pseudowords $(\beta=-.253, p=.042)$. Reading did not relate to spelling of consistent pseudowords, but a significant relation was found with RAN as well as a suppression effect of VAS. When VAS was left out of the analysis, spelling of consistent pseudowords still related to RAN ( $\beta=-.220, p=.037)$.

A number of additional analyses were conducted to exclude several potential explanations for these findings. First, the results were the same when we included only children with complete data on all the variables in the regression analyses $(N=125 ; 72$ first graders, 53 second graders), with a few exceptions. In the model without reading, RAN was not a significant predictor for spelling of inconsistent pseudowords when VAS was left out of the analysis, and the suppression effect of VAS did not reach significance for spelling of inconsistent words in the analyses that included reading. The results also changed only minimally when we included only native monolingual speakers of Dutch $(N=110 ; 58$ first graders, 52 second

Table 3 Standardized Beta Coefficients from the Regression Analyses

\begin{tabular}{lccllc}
\hline & \multicolumn{2}{c}{ Word spelling } & & \multicolumn{2}{l}{ Pseudoword spelling } \\
\cline { 2 - 3 } \cline { 5 - 6 } & Consistent & Inconsistent & & Consistent & Inconsistent \\
\hline Without reading & & & & \\
PA & $-.225^{*}$ & $-.386^{* *}$ & & $-.223^{*}$ & $-.266^{* *}$ \\
RAN & $-.345^{* *}$ & $-.350^{* *}$ & & $-.271^{* *}$ & $-.272^{* *}$ \\
VAS & -.031 & .022 & & $.260^{* *}$ & $.327^{* *}$ \\
Total $R^{2}$ & .228 & .339 & & .119 & .153 \\
With reading & & & & \\
Reading & $-.457^{* *}$ & $-.765^{* *}$ & & -.039 & $-.360^{* *}$ \\
PA & -.055 & -.096 & & -.207 & -.116 \\
RAN & -.163 & -.046 & & $-.256^{*}$ & -.129 \\
VAS & .060 & $.170^{*}$ & & $.266^{* *}$ & $.388^{* *}$ \\
Total $R^{2}$ & .323 & .603 & .120 & .209 \\
\hline
\end{tabular}

$* p<.05, * * p<.01$ 
graders). In the model without reading, the effect of RAN on spelling of inconsistent pseudowords was only marginally significant, and in the model with reading, the effect of RAN on spelling of consistent words was significant.

Secondly, we chose the number of spelling errors per item as the main outcome measure, because such a score best reflects differences in spelling ability between children. However, previous studies are often based on a binary coding of spelling as correct or incorrect. In addition, the items in the current study can be expected to particularly elicit errors in vowel spelling. We therefore also analyzed the proportion of vowel incorrect and the proportion of overall spelling incorrect. Concerning the spelling vowel incorrect, few errors were made in consistent items for both words (Grade 1: $\mathrm{M}=.06, S D=.05$; Grade 2: $\mathrm{M}=.04$, $S D=.05$ ) and pseudowords (Grade 1: $\mathrm{M}=.03, S D=.08$; Grade 2: $\mathrm{M}=.06$, $S D=.11)$, whereas many errors were made in inconsistent items for both words (Grade 1: $\mathrm{M}=.84, S D=.21$; Grade 2: $\mathrm{M}=.53, S D=.27$ ) and pseudowords (Grade 1: $\mathrm{M}=.69, S D=.33$; Grade $2: \mathrm{M}=.72, S D=.31)$. The RM ANOVA results for the vowel incorrect scores were the same as reported above for the number of spelling errors per item. Regression analyses indicated that the effect of PA was slightly stronger in all analyses, and was significant for spelling of consistent pseudowords when reading was also included in the analyses. The effect of RAN, in contrast, was weaker and significant only for spelling of inconsistent words when reading was not included in the analyses. The effect of reading was similar, but not significant for spelling of inconsistent pseudowords.

The overall spelling incorrect scores were low in consistent items for both words (Grade 1: $\mathrm{M}=.19, S D=.12$; Grade 2: $\mathrm{M}=.10, S D=.11$ ) and pseudowords (Grade $1: \mathrm{M}=.18, S D=.18$; Grade $2: \mathrm{M}=.16, S D=.17)$, whereas many errors were made in inconsistent items for both words (Grade 1: $\mathrm{M}=.89, S D=.18$; Grade 2: $\mathrm{M}=.63$, $S D=.25$ ) and pseudowords (Grade 1: $\mathrm{M}=.77, S D=.27$; Grade $2: \mathrm{M}=.79, S D=.27$ ). The RM ANOVA results were the same as reported above for the number of spelling errors per item. For the proportion of overall spelling incorrect, regression results were only slightly different for inconsistent pseudowords. The effect of RAN was not significant when reading was not included in the analysis, and the effect of reading was not significant.

Finally, we used regression analyses to examine whether the relation of cognitive correlates with spelling outcomes was different for Grade 1 and Grade 2. To this end we specified regression analyses for each cognitive correlate separately with each spelling outcome and included the interaction between Grade and the specific correlate in addition to the main effects. The findings are presented in Table 4. For spelling of words, none of the interaction effects were significant, but for spelling of pseudowords there were some significant interaction effects. First, the relation between PA and spelling of both consistent and inconsistent pseudowords is stronger in Grade 2 than in Grade 1. Second, the relation between VAS and spelling of inconsistent pseudowords differed across grades. In Grade 2 the effect of VAS was significant and in the expected direction. In Grade 1, however, the effect was also significant, but higher scores on VAS were associated with more errors in spelling. And third, the relation between reading and spelling of consistent pseudowords was larger in Grade 2 than in Grade 1. 


\section{Discussion}

This study set out to evaluate the contribution of cognitive skills to early spelling performance, in Dutch Grade 1 and 2 children. Specifically, a distinction was made between spelling of words and pseudowords and between phonologically consistent and inconsistent targets. We included visual attention span (VAS) as a cognitive correlate, next to phoneme awareness (PA) and rapid automatized naming (RAN), whose contributions to spelling have been assessed before. Word reading was also included and was expected to subsume variance from the cognitive correlates. Our results demonstrate that children's number of spelling errors differ for the different target types and between grades. They also showed that the contribution of the correlates differed across target types and grades. Both findings are discussed in more detail below. Most importantly, the cognitive correlates only captured a limited amount of variance in spelling errors.

As expected, the number of spelling errors of Grade 2 children were lower than of Grade 1 children, and there were more errors in spelling of inconsistent targets than of consistent ones. The effect of consistency was most pronounced in Grade 1, as first graders spelled inconsistent words especially poorly. Spelling of pseudowords was not necessarily more difficult than spelling of words, but interesting group differences emerged. In Grade 1 word spelling led to more errors, whereas in Grade 2, pseudoword spelling did. There thus seems to be a difference between learning to spell words and pseudowords, as also reported by Lervåg and Hulme (2010), as well as between spelling consistent and inconsistent targets, as also previously reported (e.g., de Bree, van der Ven, \& van der Maas, 2017; Keuning \& Verhoeven, 2008; Kim et al., 2016). These findings indicate that future studies into spelling ability should distinguish different target types, rather than study spelling ability as a single construct.

In terms of cognitive correlates of spelling ability, PA and RAN were significant predictors of spelling consistent and inconsistent words, and RAN related to spelling

Table 4 Standardized beta coefficients from the interaction analyses

\begin{tabular}{|c|c|c|c|c|}
\hline & \multicolumn{2}{|c|}{ Word spelling } & \multicolumn{2}{|c|}{ Pseudoword spelling } \\
\hline & Consistent & Inconsistent & Consistent & Inconsistent \\
\hline PA & $-.313 * *$ & $-.471 * *$ & .056 & .043 \\
\hline Grade & $-.375^{*}$ & $-.605 * *$ & $.320 *$ & .188 \\
\hline PA $*$ grade & .001 & .082 & $-.519 * *$ & $-.505 * *$ \\
\hline RAN & $-.292^{*}$ & $-.256^{*}$ & $-.294 *$ & $-.355^{* *}$ \\
\hline Grade & -.248 & $-.716^{*}$ & .000 & -.817 \\
\hline RAN * Grade & .020 & .279 & .088 & .839 \\
\hline VAS & $-.228 *$ & $-.258 * *$ & .118 & $.401 * *$ \\
\hline Grade & -.400 & $-.653 * *$ & .077 & $.558 *$ \\
\hline VAS * Grade & .031 & .108 & -.172 & $-.881 * *$ \\
\hline Reading & $-.464 * *$ & $-.656^{* *}$ & -.025 & -.197 \\
\hline grade & -.156 & $-.350^{*}$ & .448 & .207 \\
\hline Reading * Grade & -.018 & .096 & $-.546^{*}$ & -.318 \\
\hline
\end{tabular}

$* p<.05, * * p<.01$ 
of consistent and inconsistent pseudowords. VAS did not relate to the number of spelling errors in these target types. Together, however, these skills explained only a small amount of the variance in spelling performance. When reading ability was included as a correlate, the amount of explained variance increased and effects of the cognitive correlates disappeared, except for the consistent pseudowords, where reading did not contribute and RAN was the only correlate of the number of errors made. The contribution of word reading to inconsistent word spelling was substantial. All these findings proved to be robust, as the pattern of results was the same when the proportion of items incorrect or the proportion of vowels incorrect were analyzed, and also when children who were not monolingual speakers of Dutch or who had incomplete data were removed from the analyses. These findings align with those of previous studies that have compared different spelling error scores and found a consistent pattern across the different scoring methods (Clemens, Oslund, Simmons, \& Simmons, 2014; Ritchey, Coker, \& McCraw, 2010).

These results confirm our expectation that PA plays a role in spelling and partly agree with previous results on early spelling (e.g., Lervåg \& Hulme, 2010; Veber Nielsen \& Juul, 2016). The ability to separate phonemes in spoken words seems relevant for spelling of words that are spelled like they sound and those that are not. It should be noted that we specifically looked at spelling errors. If children have not acquired the inconsistent spelling patterns, they appear to rely on phoneme-grapheme-conversion in spelling the targets. Their spelling, derived on the basis of speech sounds, is incorrect but shows a relationship with PA. In support of this explanation, the relation with PA was slightly stronger when we only analyzed vowel errors, which are an example of a phonologically based spelling error. In contrast to our expectations PA was not strongly related to spelling of pseudowords. However, this seems to be due mainly to differences in the effect of PA across grades, as discussed below.

The findings also show that RAN contributes to spelling of all target types even in early spellers, but VAS does not. These findings speak to the issue of which skills RAN and VAS measure. The contribution of RAN already in Grade 1 as well as the contribution regardless of target type suggests that it taps mainly phonology-orthography connections at the sublexical level (Moll et al., 2009) rather than lexical orthographic skills (Conrad \& Levy, 2007; Wolf \& Bowers, 1999). These findings are thus taken to align with the assumption that RAN taps the efficiency of the alphabetic principle (Moll et al., 2009). Future studies that examine the role of sublexical and lexical orthographic knowledge in spelling of different target types are called for.

The findings on VAS are more difficult to interpret. In our data, VAS performance is related to spelling of consistent and inconsistent words but not to pseudoword spelling. Moreover, there is no significant contribution of VAS to spelling over and above PA and RAN. Although the effects of VAS on spelling are thus rather limited, the findings seem to favour the interpretation of VAS as a visual task (e.g., Zoubrinetzky et al., 2014) rather than a measure of the parallel processing of sublexical orthographic units (van den Boer et al., 2015). In the latter view, a contribution from an early age onwards on all targets would be anticipated. At the same time, however, an effect of VAS is visible in pseudoword spelling in Grade 2. Such findings run counter to the interpretation of VAS being a visual task, as, if anything, contribution to word spelling would be expected. Interestingly, VAS was related to reading ability 
in these young children, so it is not the case that VAS could not be measured reliably or that it plays no role in literacy skills at all at this age. These findings show the need for a longitudinal study into the relationship between VAS and spelling to be able to draw firm conclusions about the relationship between the two and the nature of VAS.

There were similarities and differences in the contributions that cognitive correlates made across grades. For word spelling, the cognitive correlates were the same for Grade 1 and Grade 2, but for pseudoword spelling the effects of PA and reading were stronger in Grade 2 than in Grade 1 and the effect of VAS was in the anticipated direction in Grade 2, but not in Grade 1. In general the findings on pseudoword spelling in Grade 2 were as expected, but the findings on pseudoword spelling in Grade 1 were not. First graders made many errors in spelling the pseudowords, which were not related to cognitive correlates as expected. These findings might be taken to mean that pseudoword spelling in Grade 1 elicited a range of spelling strategies in these very young spellers that are not captured by the variables in our study. These findings agree with studies that have found developmental shifts in spelling strategies (e.g., Farrington-Flint, Stash, \& Stiller, 2008; McGeown, Medford, \& Moxon, 2013). They also speak to studies that have found that prephonological spellers show some knowledge of graphotactic patterns (e.g. Kessler, Pollo, Treiman, \& Cardoso-Martins, 2013) and that older prephonological spellers produce more wordlike spellings (Treiman, Kessler, Boland, Clocksin, \& Chen, 2018). This means that young spellers already have different sources of information at their disposal that they might be relying on instead of phonological information. However, on the basis of our study, we cannot make any claims about the strategies the children relied on. In order to understand these findings more fully, research into strategy use and the subsequent relationship with cognitive correlates would be required (e.g., McGeown et al., 2013). The findings thus indicate that research into cognitive correlates needs to take place in tandem with assessment of other factors, such as item characteristics (Kim et al., 2016) as well as strategies children use to spell.

The finding that most of the contributions of the cognitive correlates disappeared once reading was entered in the regression analyses confirms the importance of reading in (early) spelling (e.g., Desimoni et al., 2012; Keuning \& Verhoeven, 2008; Leppänen et al., 2006), as well as our hypothesis that the correlates included in this study relate to spelling mainly because of their relation with reading. It also relates to the fact that the correlates included in this study, as well as most previous studies, are those originally related to reading. PA can be related to spelling in a straightforward manner, as in a typical spelling task speech is heard and an operation has to be conducted on it to transfer the information to the written modality. In contrast, RAN and VAS are tasks that demand the opposite activity: visual information is displayed and needs to be converted to speech. Their relation with spelling is thus less obvious. Furthermore, the cognitive correlates were only able to capture a small amount of variance of spelling. These results render interpretations and steps for further research. For instance, more knowledge is needed on other cognitive correlates, that are specifically related to spelling. Future studies should not focus (only) on reading-based correlates, but those that can be conceived to relate to spelling, such as vocabulary knowledge, morphological awareness, and orthographic learning (e.g., Kim, Apel, \& Al-Otaiba, 2013), as well as measures of strategy use or 
self-regulation, which are also likely to influence spelling development (e.g., Aram, Abiri, \& Elad, 2014; Graham \& Santangelo, 2014; McGeown et al., 2013; Williams, Walker, Vaughn, \& Wanzek, 2017).

\section{Limitations and future directions}

In the current study, we specifically aimed to establish the relation between cognitive correlates and different target types, in combination with the assessment of VAS. The study is qualified by a number of limitations. First, our study did not include verbal short-term memory and letter knowledge, two measures that are generally associated with literacy skills (e.g., Georgiou et al., 2012; Lervåg \& Hulme, 2010). Furthermore, we had not included skills that are more closely related to spelling, such as morphological knowledge, vocabulary and print exposure. Our starting point was to look into cognitive skills that are often assessed in relation to reading (PA and RAN, and more recently VAS) and are (therefore) taken to relate to spelling as well. The findings indicate that this is not necessarily the case and, more importantly, that a substantial amount of variance was unexplained. Future studies should therefore focus on the relation of spelling with spelling-specific predictors, which we do not yet know sufficiently about.

Secondly, we included measures of alphanumeric RAN (digits and letters), but not of nonalphanumeric RAN (colours and pictures). RAN letters and RAN digits have been shown to reflect the same skill, but mainly from age 10 onward (van den Bos et al., 2002). In the current study we checked whether including only RAN digits or only RAN letters affected the findings, but we did not find systematic differences. By including only alphanumeric RAN we specifically looked into the relationship between phonological and written information. Our study cannot make any claims about the general mechanism of cross-modal mapping or access that occurs in RAN (e.g. Jones, Branigan, Hatzidaki, \& Obregón, 2010; Vaessen, Gerretsen, \& Blomert, 2009). We opted for inclusion of alphanumeric RAN only as we wanted to assess the specific phonology and orthography association. Furthermore, it has been reported that nonalphanumeric RAN does not relate to spelling (Donker, Kroesbergen, Slot, van Viersen, \& de Bree, 2016). A longitudinal study of both nonalphanumeric and alphanumeric RAN is required to gain more insight into the general and specific contributions of RAN to spelling.

In terms of the spelling targets that were included, there are three limitations. The first is that the number of phonologically consistent and inconsistent targets was not equal. The second is that the phonologically consistent targets consisted of both mono- and bisyllabic targets, whereas the inconsistent targets consisted of bisyllabic items (and one trisyllabic target). Although we controlled for item length in terms of number of graphemes, syllable length is thus a potential confound in the outcomes for the number of errors that we did not control for. Third, spelling of only one type of phonological consistency/orthographic rule was assessed rather than a larger scope (as in Kim et al., 2016). At the same time, such a narrow focus does provide insight into the different mechanisms involved in spelling these types of targets.

Fourth, our study focused on the relationship between spelling and cognitive correlates in one language only. The relationship between reading and spelling could be influenced by transparency, for instance. Being able to read 
in a symmetric transparent language would imply that spelling should also be acquired. In contrast, in opaque orthographies, reading is easier than spelling and the relationship between reading and spelling is not 1:1. For semi-transparent orthographies, this relationship is present for consistent words but not for inconsistent words. At the same time, orthographic knowledge is required for spelling inconsistent targets. This knowledge can be acquired through instruction as well as exposure to words. Thus, reading could play a different role on word spelling dependent on the orthography, word type and phase of development. To gain further insight into these associations, cross-linguistic studies, such as those by Georgiou et al. (2012) and Moll et al. (2014) are required, combined with different types of targets to be spelled.

Finally, we limited ourselves to concurrent correlates of spelling, and did not assess longitudinal relationships (as in e.g., Georgiou et al., 2012; Kim et al., 2016; Lervåg \& Hulme, 2010; Veber Nielsen \& Juul, 2016). Patterns might differ if assessed longitudinally. Specifically, it is not clear to what extent our findings for early spelling performance apply across development and whether there are differential effects of cognitive correlates on spelling outcomes. The influence of the correlates might differ for children depending on children's spelling ability. Such findings have been reported in other studies (Kim et al., 2016; Lervåg \& Hulme, 2010) and are important for understanding the path to spelling acquisition. The present findings show how cognitive correlates contribute concurrently on early spelling, which is an important stepping stone for further (longitudinal) research.

Despite the limitations, our study showed that spelling performance depends on the types of items studied, as spelling of words and pseudowords and of consistent and inconsistent targets can differ. Furthermore, reading-based cognitive correlates are able to account for only a small amount of variance in spelling performance, and their effects are actually better captured by reading skill itself. We propose that this is due to the nature of these cognitive skills, which stem from the reading literature rather than spelling processes. Identifying these gaps in our knowledge on spelling development, and knowing what we do not know, is a further step to insight in spelling acquisition. On the basis of these findings, we therefore plea for spelling-centered studies, in which child-based abilities directly related to spelling are examined while studying different types of targets.

Acknowledgements We are grateful to the children and their teachers for their participation. We would like to thank the student assistants involved in data collection. This research did not receive any specific grant from funding agencies in the public, commercial, or not-for-profit sectors.

Open Access This article is distributed under the terms of the Creative Commons Attribution 4.0 International License (http://creativecommons.org/licenses/by/4.0/), which permits unrestricted use, distribution, and reproduction in any medium, provided you give appropriate credit to the original author(s) and the source, provide a link to the Creative Commons license, and indicate if changes were made.

\section{Appendix 1}

See Table 5 . 
Table 5 Overview of real word stimuli

\begin{tabular}{|c|c|c|c|c|c|}
\hline Target & Translation & $\begin{array}{l}\text { Phonological consistency } \\
\text { or orthographic rule }\end{array}$ & Nr syllables & $\begin{array}{l}\text { CELEX } \\
\text { frequency per } \\
\text { million }\end{array}$ & AoA* \\
\hline been & Leg & Consistent & 1 & 188,0182 & 4.09 \\
\hline boomhut & Treehouse & Consistent & 2 & n.a. & 6.47 \\
\hline buurman & Neighbour & Consistent & 2 & 19,002 & 5.75 \\
\hline doolhof & Labyrinth/maze & Consistent & 2 & 7 & 6.96 \\
\hline droom & Dream & Consistent & 1 & 118,9871 & 5.36 \\
\hline duur & Expensive & Consistent & 1 & 120,0052 & 6.46 \\
\hline feestdag & National holiday & Consistent & 2 & 8,9991 & 7.9 \\
\hline koopman & Merchant & Consistent & 2 & 16,9981 & 9.78 \\
\hline krul & Mark as correct & Consistent & 1 & 12,0005 & 5.73 \\
\hline leesles & Reading lesson & Consistent & 2 & 5,0001 & n.a. \\
\hline maan & Moon & Consistent & 1 & 64,998 & 5.34 \\
\hline noot & Nut & Consistent & 1 & 19,002 & 5.54 \\
\hline pen & Pen & Consistent & 1 & 19,002 & 5.73 \\
\hline rugzak & Backpack & Consistent & 2 & 8,0002 & 5.83 \\
\hline sok & Sock & Consistent & 1 & 12,9987 & 4.65 \\
\hline spaarpot & Piggy bank & Consistent & 2 & 1 & 5.99 \\
\hline speel & Play & Consistent & 1 & n.a. & n.a. \\
\hline stuur & Steer & Consistent & 1 & 44,0048 & 5.6 \\
\hline tas & Bag & Consistent & 1 & 38,0014 & 5.37 \\
\hline vraag & Question & Consistent & 1 & 475,9923 & 5 \\
\hline vuurwerk & Fireworks & Consistent & 2 & 5,0003 & 6.65 \\
\hline warm & Warm & Consistent & 1 & 158,0156 & 4.71 \\
\hline zes & Six & Consistent & 1 & 129,987 & 4.5 \\
\hline zon & Sun & Consistent & 1 & 46,0045 & 4.35 \\
\hline haaksteek & Crochet stitch & Consistent & 2 & n.a. & n.a. \\
\hline adem & Breath & Inconsistent: orth rule & 2 & 86,9961 & 5.68 \\
\hline bami & Bami & Inconsistent: orth rule & 2 & 1 & 11.84 \\
\hline benen & Legs & Inconsistent: orth rule & 2 & 2,9999 & 5.56 \\
\hline dromen & Dreams & Inconsistent: orth rule & 2 & 65,9933 & 4.84 \\
\hline dure & Expensive & Inconsistent: orth rule & 2 & n.a. & \\
\hline fluweel & Velvet & Inconsistent: orth rule & 2 & 5,0003 & 9.53 \\
\hline hagel & Hail & Inconsistent: orth rule & 2 & 4,0004 & 7.02 \\
\hline hekel & Dislike & Inconsistent: orth rule & 2 & 19,002 & 8.44 \\
\hline hotel & Hotel & Inconsistent: orth rule & 2 & 92,0026 & 6.78 \\
\hline juni & June & Inconsistent: orth rule & 2 & 41,9952 & 6.05 \\
\hline kleding & Clothing & Inconsistent: orth rule & 2 & 22,9985 & 6.34 \\
\hline kobalt & Cobalt & Inconsistent: orth rule & 2 & 1 & 13.06 \\
\hline krater & Crater & Inconsistent: orth rule & 2 & 5,0003 & 9.03 \\
\hline lepel & Spoon & Inconsistent: orth rule & 2 & 18,0011 & 4.19 \\
\hline manen & Moons & Inconsistent: orth rule & 2 & 8,0002 & 9.17 \\
\hline muziek & Music & Inconsistent: orth rule & 2 & 115,0006 & 4.84 \\
\hline
\end{tabular}


Table 5 (continued)

\begin{tabular}{|c|c|c|c|c|c|}
\hline Target & Translation & $\begin{array}{l}\text { Phonological consistency } \\
\text { or orthographic rule }\end{array}$ & $\mathrm{Nr}$ syllables & $\begin{array}{l}\text { CELEX } \\
\text { frequency per } \\
\text { million }\end{array}$ & $\mathrm{AoA}^{*}$ \\
\hline negen & Nine & Inconsistent: orth rule & 2 & 51,0035 & 4.86 \\
\hline noten & Nuts & Inconsistent: orth rule & 2 & 1 & 6.67 \\
\hline oven & Oven & Inconsistent: orth rule & 2 & 12,0005 & 6.37 \\
\hline pekel & Brine & Inconsistent: orth rule & 2 & 1,9999 & 10.34 \\
\hline ruzie & Fight & Inconsistent: orth rule & 2 & 43,0031 & 4.9 \\
\hline spelen & Play & Inconsistent: orth rule & 2 & 380,0143 & 3.9 \\
\hline sturen & Steer & Inconsistent: orth rule & 2 & 100,9951 & 5.9 \\
\hline tribune & Stand & Inconsistent: orth rule & 3 & 8,0002 & 8.55 \\
\hline tropen & Tropics & Inconsistent: orth rule & 2 & 4,0004 & 10.87 \\
\hline tube & Tube & Inconsistent: orth rule & 2 & 4,0004 & 8.01 \\
\hline turen & Gaze & Inconsistent: orth rule & 2 & 19,002 & 9.93 \\
\hline vogel & Bird & Inconsistent: orth rule & 2 & 96,0064 & 4.24 \\
\hline vragen & Question & Inconsistent: orth rule & 2 & 804,0812 & 4.9 \\
\hline wake & Virgil & Inconsistent: orth rule & 2 & 1 & n.a. \\
\hline water & Water & Inconsistent: orth rule & 2 & 363,9988 & 3.67 \\
\hline zebra & Zebra & Inconsistent: orth rule & 2 & 1 & 6.15 \\
\hline zomer & Summer & Inconsistent: orth rule & 2 & 81,0028 & 5.33 \\
\hline
\end{tabular}

*Age of Acquisition values are derived from Brysbaert et al. 2014

\section{Appendix 2}

See Table 6. 
Table 6 Overview of pseudoword stimuli

\begin{tabular}{lll}
\hline Target & Phonological consistency & Nr syllables \\
\hline goop & Consistent & 1 \\
kluur & Consistent & 1 \\
muut & Consistent & 1 \\
naag & Consistent & 1 \\
reen & Consistent & 1 \\
snaap & Consistent & 1 \\
veek & Consistent & 1 \\
woom & Consistent & 1 \\
dovel & Inconsistent: orthographic rule & 2 \\
dupie & Inconsistent: orthographic rule & 2 \\
fatel & Inconsistent: orthographic rule & 2 \\
gener & Inconsistent: orthographic rule & 2 \\
gover & Inconsistent: orthographic rule & 2 \\
grepel & Inconsistent: orthographic rule & 2 \\
waber & Inconsistent: orthographic rule & 2 \\
wubus & Inconsistent: orthographic rule & 2 \\
gopen & Inconsistent: orthographic rule & 2 \\
kluren & Inconsistent: orthographic rule & 2 \\
muten & Inconsistent: orthographic rule & 2 \\
nagen & Inconsistent: orthographic rule & 2 \\
renen & Inconsistent: orthographic rule & 2 \\
snapen & Inconsistent: orthographic rule & 2 \\
veken & Inconsistent: orthographic rule & 2 \\
women & Inconsistent: orthographic rule & 2 \\
\hline & & \\
\hline
\end{tabular}

\section{References}

Abbott, R., Berninger, V. W., \& Fayol, M. (2010). Longitudinal relationships of levels of language in writing and between writing and reading in grades 1 to 7. Journal of Educational Psychology, 102, 281-298. https://doi.org/10.1037/a001931.

Al-Otaiba, S., Puranik, C., Rouby, A. D., Greulich, L., Folsom, J. S., \& Lee, J. (2010). Predicting kindergartners' end of year spelling ability from their reading, alphabetic, vocabulary, and phonological awareness skills, and prior literacy experiences. Learning Disability Quarterly, 33, 173-181. https://doi.org/10.1177/073194871003300306.

Aram, D., Abiri, S., \& Elad, L. (2014). Predicting early spelling: the contribution of children's early literacy, private speech during spelling, behavioral regulation, and parental spelling support. Reading and Writing: An Interdisciplinary Journal, 27, 685-707. https://doi.org/10.1007/s1114 5-013-9466-z.

Baayen, R. H., Piepenbrock, R., \& Van Rijn, H. (1993). The CELEX lexical database. CD-ROM. Philadelphia, PA: Linguistic Data Consortium, University of Pennsylvania.

Bosman, A., Vonk, W., \& van Zwam, M. (2006). Spelling consistency affects reading in young Dutch readers with and without dyslexia. Annals of Dyslexia, 56, 271-300. https://doi.org/10.1007/ s11881-006-0012-4.

Bosse, M. L., Chaves, N., Largy, P., \& Valdois, S. (2015). Orthographic learning during reading: The role of whole-word visual processing. Journal of Research in Reading, 38, 141-158. https://doi. org/10.1111/j.1467-9817.2012.01551.x. 
Bosse, M. L., Tainturier, M. J., \& Valdois, S. (2007). Developmental dyslexia: The visual attention span deficit hypothesis. Cognition, 104, 198-230. https://doi.org/10.1016/j.cogni tion.2006.05.009.

Bosse, M. L., \& Valdois, S. (2009). Influence of the visual attention span on child reading performance: A cross-sectional study. Journal of Research in Reading, 32, 230-253. https://doi.org/10. 1111/j.1467-9817.2008.01387.x.

Brus, B., \& Voeten, B. (1995). Eén minuut test vorm A en B: Verantwoording en handleiding (One Minute Test manual). Lisse: Swets \& Zeitlinger.

Brysbaert, M., Stevens, M., De Deyne, S., Voorspoels, W., \& Storms, G. (2014). Norms of age of acquisition and concreteness for 30,000 Dutch words. Acta Psychologica, 150, 80-84. https:// doi.org/10.1016/j.actpsy.2014.04.010.

Caravolas, M., Lervåg, A., Mousikou, P., Efrim, C., Litavský, M., Onochie-Quintanilla, E., et al. (2012). Common patterns of prediction of literacy development in different alphabetic orthographies. Psychological Science, 23, 678-686. https://doi.org/10.1177/0956797611434536.

Caravolas, M., Volín, J., \& Hulme, C. (2005). Phoneme awareness is a key component of alphabetic literacy skills in consistent and inconsistent orthographies: Evidence from Czech and English children. Journal of Experimental Child Psychology, 92, 107-139. https://doi.org/10.1016/j. jecp.2005.04.003.

Clemens, N. H., Oslund, E. L., Simmons, L. E., \& Simmons, D. (2014). Assessing spelling in kindergarten: Further comparison of scoring metrics and their relation to reading skills. Journal of School Psychology, 52, 49-61. https://doi.org/10.1016/j.jsp.2013.12.005.

Conrad, N. J., \& Levy, B. A. (2007). Letter processing and the formation of memory representations in children with naming speed deficits. Reading and Writing: An Interdisciplinary Journal, 20, 201223. https://doi.org/10.1007/s11145-006-9028-8.

de Bree, E., Geelhoed, J., \& van den Boer, M. (2018). Overruled! Implicit cues rather than an orthographic rule determine Dutch children's vowel spelling. Learning and Instruction, 56, 30-41. https ://doi.org/10.1016/j.learninstruc.2018.03.006.

de Bree, E., van der Ven, S., \& van der Maas, H. (2017). The voice of Holland: Allograph production in written Dutch past tense inflection. Language Learning and Development, 13, 215-240. https://doi. org/10.1080/15475441.2016.1217777.

de Jong, P. F., \& van der Leij, A. (2003). Developmental changes in the manifestation of a phonological deficit in dyslexic children learning to read a regular orthography. Journal of Educational Psychology, 95, 22-40. https://doi.org/10.1037/0022-0663.95.1.22.

Desimoni, M., Scalisi, T. G., \& Orsolini, M. (2012). Predictive and concurrent relations between literacy skills in grades 1 and 3: A longitudinal study of Italian children. Learning and Instruction, 22, 340353. https://doi.org/10.1016/j.learninstruc.2012.02.002.

Donker, M., Kroesbergen, E., Slot, E., Van Viersen, S., \& De Bree, E. (2016). Alphanumeric and nonalphanumeric rapid automatized naming in children with reading and/or spelling difficulties and mathematical difficulties. Learning and Individual Differences, 47, 80-87. https://doi.org/10.1016/j. lindif.2015.12.011.

Farrington-Flint, L., Stash, A., \& Stiller, J. (2008). Monitoring variability and change in children's spelling strategies. Educational Psychology, 28, 133-149. https://doi.org/10.1080/01443410701471850.

Furnes, B., \& Samuelsson, S. (2011). Phonological awareness and rapid automatized naming predicting early development in reading and spelling: Results from a cross-linguistic longitudinal study. Learning and Individual Differences, 21, 85-95. https://doi.org/10.1016/j.lindif.2010.10.005.

Georgiou, G. K., Torppa, M., Manolitsis, G., Lyytinen, H., \& Parrila, R. (2012). Longitudinal predictors of reading and spelling across languages varying in orthographic consistency. Reading and Writing: An Interdisciplinary Journal, 25, 321-346. https://doi.org/10.1007/s11145-010-9271-x.

Germano, G. D., Reilhac, C., Capellini, S. A., \& Valdois, S. (2014). The phonological and visual basis of developmental dyslexia in Brazilian Portuguese reading children. Frontiers in Psychology, 5, 1169. https://doi.org/10.3389/fpsyg.2014.01169.

Graham, S., Harris, K. R., \& Hebert, M. (2011). It is more than just the message: Analysis of presentation effects in scoring writing. Focus on Exceptional Children, 44, 1-12. https://doi.org/10.1201/b1096 2-2.

Graham, S., \& Santangelo, T. (2014). Does spelling instruction make students better spellers, readers, and writers? A meta-analytic review. Reading and Writing: An Interdisciplinary Journal, 27, 17031743. https://doi.org/10.1007/s11145-014-9517-0. 
Harrison, G., Goegan, L. D., Jalbert, R., McManus, K., Sinclair, K., \& Spurling, J. (2016). Predictors of spelling and writing skills in first- and second-language learners. Reading and Writing: An Interdisciplinary Journal, 29, 69-89. https://doi.org/10.1007/s11145-015-9580-1.

Hawelka, S., \& Wimmer, H. (2008). Visual target detection is not impaired in dyslexic readers. Vision Research, 48, 850-852. https://doi.org/10.1016/j.visres.2007.11.003.

Jones, M. W., Branigan, H. P., Hatzidaki, A., \& Obregón, M. (2010). Is the 'naming' deficit in dyslexia a misnomer? Cognition, 116, 56-70. https://doi.org/10.1016/j.cognition.2010.03.015.

Kessler, B., Pollo, T. C., Treiman, R., \& Cardoso-Martins, C. (2013). Frequency analyses of prephonological spellings as predictors of success in conventional spelling. Journal of Learning Disabilities, 46, 252-259. https://doi.org/10.1177/0022219412449440.

Keuning, J., \& Verhoeven, L. (2008). Spelling development throughout elementary grades: the Dutch case. Learning and Individual Differences, 18, 459-470. https://doi.org/10.1016/j.lindi f.2007.12.001.

Kim, Y. S. (2010). Componential skills in early spelling development in Korean. Scientific Studies of Reading, 14, 137-158. https://doi.org/10.1080/10888430903034812.

Kim, Y. S., Apel, K., \& Al Otaiba, S. (2013). The relation of linguistic awareness and vocabulary to word reading and spelling for first-grade students participating in response to intervention. Language, Speech, and Hearing Services in Schools, 44, 337-347. https://doi. org/10.1044/0161-1461(2013/12-0013).

Kim, Y. S. G., Petscher, Y., \& Park, Y. (2016). Examining word factors and child factors for acquisition of conditional sound-spelling consistencies: A longitudinal study. Scientific Studies of Reading, 20, 265-282. https://doi.org/10.1080/10888438.2016.1162794.

Landerl, K., \& Reitsma, P. (2005). Phonological and morphological consistency in the acquisition of vowel duration spelling in Dutch and German. Journal of Experimental Child Psychology, 92, 22-44. https://doi.org/10.1016/j.jecp.2005.04.005.

Landerl, K., \& Wimmer, H. (2008). Development of word reading fluency and spelling in a consistent orthography: An 8-year follow-up. Journal of Educational Psychology, 100, 150-161. https://doi. org/10.1037/0022-0663.100.1.150.

Leppänen, U., Nieme, P., Aunola, K., \& Nurmi, J. (2006). Development of reading and spelling Finnish from preschool to grades 1 and 2. Scientific Studies of Reading, 10, 3-30. https://doi.org/10.1207/ s1532799xssr1001_2.

Lervåg, A., \& Hulme, C. (2010). Predicting the growth of early spelling skills: Are there heterogeneous developmental trajectories? Scientific Studies of Reading, 14, 485-513. https://doi. org/10.1080/10888431003623488.

Maassen, G. H., \& Bakker, A. B. (2001). Suppressor variables in path models. Definitions and interpretations. Sociological Methods and Research, 30, 241-270. https://doi.org/10.1177/004912410103000 2004.

McGeown, S. P., Medford, E., \& Moxon, G. (2013). Individual differences in children's reading and spelling strategies and the skills supporting strategy use. Learning and Individual Differences, 28, 75-81. https://doi.org/10.1016/j.lindif.2013.09.013.

Moll, K., Fussenegger, B., Willburger, E., \& Landerl, K. (2009). RAN is not a measure of orthographic processing. Evidence from the asymmetric German orthography. Scientific Studies of Reading, 13, 1-25. https://doi.org/10.1080/10888430802631684.

Moll, K., Ramus, F., Bartling, J., Bruder, J., Kunze, S., Neuhoff, N., et al. (2014). Cognitive mechanisms underlying reading and spelling development in five European orthographies. Learning and Instruction, 29, 65-77. https://doi.org/10.1016/j.learninstruc.2013.09.003.

Nikolopoulos, D., Goulandris, N., Hulme, C., \& Snowling, M. J. (2006). The cognitive bases of learning to read and spell in Greek: Evidence from a longitudinal study. Journal of Experimental Child Psychology, 94, 1-17. https://doi.org/10.1016/j.jecp.2005.11.006.

Perfetti, C. A. (1997). The psycholinguistics of spelling and reading. In C. A. Perfetti, L. Rieben, \& M. Fayol (Eds.), Learning to Spell: Research, Theory, and Practice Across Languages (pp. 21-38). Mahwah: Lawrence Erlbaum Associates Publishers.

Plaza, M., \& Cohen, H. (2007). The contribution of phonological awareness and visual attention in early reading and spelling. Dyslexia an International Journal of Research and Practice, 13, 67-76. https ://doi.org/10.1002/dys.330.

Ritchey, K. D., Coker, D. L., Jr., \& McCraw, S. B. (2010). A comparison of metrics for scoring beginning spelling. Assessment for Effective Intervention, 35, 78-88. 
Savage, R., Pillay, V., \& Melidona, S. (2008). Rapid serial naming is a unique predictor of spelling in children. Journal of Learning Disabilities, 41, 235-250. https://doi.org/10.1177/0022219408315814.

Savolainen, H., Ahonen, T., Aro, M., Tolvanen, A., \& Holopainen, L. (2008). Reading comprehension, word reading and spelling as predictors of school achievement and choice of secondary education. Learning and Instruction, 18, 201-210. https://doi.org/10.1016/j.learninstruc.2007.09.017.

Tops, W., Callens, M., Van Cauwenberghe, E., Adriaens, J., \& Brysbaert, M. (2013). Beyond spelling: The writing skills of students with dyslexia in higher education. Reading and Writing: An Interdisciplinary Journal, 26, 705-720. https://doi.org/10.1007/s11145-012-9387-2.

Treiman, R., Kessler, B., Boland, K., Clocksin, H., \& Chen, Z. (2018). Statistical learning and spelling: Older prephonological spellers produce more wordlike spelling than younger prephonological spellers. Child Development, 89, e431-e443. https://doi.org/10.1111/cdev.12893.

Vaessen, A., \& Blomert, L. (2013). The cognitive linkage and divergence of spelling and reading development. Scientific Studies of Reading, 17, 89-107. https://doi.org/10.1080/10888438.2011.614665.

Vaessen, A., Gerretsen, P., \& Blomert, L. (2009). Naming problems do not reflect a second independent core deficit in dyslexia: Double deficits explored. Journal of Experimental Child Psychology, 103, 202-221. https://doi.org/10.1016/j.jecp.2008.12.004.

Valdois, S., Bosse, M. L., Ans, B., Carbonnel, S., Zorman, M., David, D., et al. (2003). Phonological and visual processing deficits can dissociate in developmental dyslexia: Evidence from two case studies. Reading and Writing: An Interdisciplinary Journal, 16, 541-572. https://doi.org/10.1023/a:10255 01406971.

Valdois, S., Bosse, M. L., \& Tainturier, M. J. (2004). The cognitive deficits responsible for developmental dyslexia: Review of evidence for a selective visual attentional disorder. Dyslexia An International Journal of Research and Practice, 10, 339-363. https://doi.org/10.1002/dys.284.

van den Boer, M., \& de Jong, P. F. (2018). Stability of visual attention span performance and its relation with reading over time. Scientific Studies of Reading, 22, 434-441. https://doi.org/10.1080/10888 438.2018.1472266.

van den Boer, M., van Bergen, E., \& de Jong, P. F. (2015). The specific relation of visual attention span with reading and spelling. Learning and Individual Differences, 39, 141-149. https://doi. org/10.1016/j.lindif.2015.03.017.

van den Bos, K. P., \& Lutje Spelberg, H. C. (2007). Continu Benoemen \& Woorden Lezen. Een test voor het diagnosticeren van taal- en leesstoornissen [CB\&WL manual]. Amsterdam: Boom Test Uitgevers.

van den Bos, K. P., Lutje Spelberg, H. C., Scheepstra, A. J. M., \& de Vries, J. R. (1994). De Klepel: Een Test Voor de Leesvaardigheid van Pseudowoorden [Klepel manual]. Lisse: Swets \& Zeitlinger.

van den Bos, K. P., Zijlstra, B. J. H., \& Lutje Spelberg, H. C. (2002). Life span data on continuousnaming speeds of numbers, letters, colors, and pictured objects, and word-reading speed. Scientific Studies of Reading, 6, 25-49. https://doi.org/10.1207/S1532799XSSR0601_02.

Veber Nielsen, A.-M., \& Juul, H. (2016). Predictors of early versus later spelling development in Danish. Reading and Writing: An Interdisciplinary Journal, 29, 245-266. https://doi.org/10.1007/s1114 5-015-9591-y.

Verhagen, W. T., Aarnoutse, C. A. J., \& van Leeuwe, J. F. J. (2010). Spelling and word recognition in grades 1 and 2: Relations to phonological awareness and naming speed in Dutch children. Applied Psycholinguistics, 31, 59-80. https://doi.org/10.1017/S0142716409990166.

Williams, K. J., Walker, M. A., Vaughn, S., \& Wanzek, J. (2017). A synthesis of reading and spelling interventions and their effects on spelling outcomes for students with learning disabilities. Journal of Learning Disabilities, 50, 286-297. https://doi.org/10.1177/0022219415619753.

Wolf, M., \& Bowers, P. G. (1999). The double-deficit hypothesis for the developmental dyslexias. Journal of Educational Psychology, 91, 415-438. https://doi.org/10.1037/0022-0663.91.3.415.

Ziegler, J. C., Pech-Georgel, C., Dufau, S., \& Grainger, J. (2010). Rapid processing of letters, digits, and symbols: What purely visual-attentional deficit in developmental dyslexia? Developmental Science, 13, F8-F14. https://doi.org/10.1111/j.1467-7687.2010.00983.x.

Zoubrinetzky, R., Bielle, F., \& Valdois, S. (2014). New insights on developmental dyslexia subtypes: Heterogeneity of mixed reading profiles. PloS ONE, 9, e99337. https://doi.org/10.1371/journ al.pone.0151015.

Publisher's Note Springer Nature remains neutral with regard to jurisdictional claims in published maps and institutional affiliations. 